\title{
Evaluasi Pelaksanaan Lkma Bentukan Dari Kegiatan PUAP Di Provinsi Lampung
}

\section{Evaluation Of Implementation Lkma Form Of PUAP Activities In Lampung Province}

\author{
Valeriana Darwis ${ }^{* 1}$ \\ *) Pusat Sosial Ekonomi dan Kebijakan Pertanian \\ 1) Email : valicfurca@gmail.com
}

\begin{abstract}
The PUAP program has been implemented since 2008 until 2015 in 52,186 villages and 6,887 LKMA have been formed. Of the 6,887 LKMA that have obtained OJK licenses as many as 115 LKMA and 6 LKMA are in Lampung Province. In implementing the PUAP program, many benefits have been obtained including: helping farmers in business capital loans, increasing income and farmers are used to borrowing money from the banking system. With these many benefits, this paper aims to evaluate how to implement Agribusiness Microfinance Institutions (LKMA) especially those that have obtained business licenses from the Financial Services Authority (OJK). Evaluation of the implementation of LKMA uses ranking methods that produce LKMA Mekar Jaya as the best LKMA and this is represented by (i) institutional aspects that already have business legality both from the Ministry of Cooperatives and from the FSA, working in the office along with the apparatus, hiring professionals outside the Gapoktan management ; (ii) implementation aspects by differentiating the amount of interest based on the type of business; each borrower is subject to a provision fee for each time he borrows and the borrower is a neighboring community that can borrow as long as it follows the conditions and has the benefit; (iii) aspects of business development where an increase in the number of borrowers and an increase in LKMA business capital from Rp 150,000,000 to Rp 1,070,000,000
\end{abstract}

Keywords: Evaluation, LKMA and PUAP

Disubmit: 13 Januari 2019 Diterima:16 Februari 2019 Disetujui: 23 Maret 2019

\section{PENDAHULUAN}

Program Pengembangan Usaha Agribisnis Pedesaan (PUAP) dibuat dengan tujuan untuk : (i) mengurangi kemiskinan dan pengangguran melalui penumbuhan dan pengembangan kegiatan usaha agribisnis di perdesaan sesuai dengan potensi wilayah; (ii) meningkatkan kemampuan pelaku usaha agribisnis, Pengurus Gapoktan, Penyuluh dan Penyelia Mitra Tani; (iii) memberdayakan kelembagaan petani dan ekonomi perdesaan untuk pengembangan kegiatan usaha agribisnis dan (iv) meningkatkan fungsi kelembagaan ekonomi petani menjadi jejaring atau mitra lembaga keuangan dalam rangka akses ke permodalan (BKP, 2009). 
Program PUAP merupakan bantuan permodalan usaha pertanian sebesar 100 juta untuk setiap satu Gapoktan di satu desa. Dalam pelaksanaannya diharapkan disetiap Gapoktan membentuk Lembaga Keuangan Mikro Agribisnis (LKMA) yang akan mengurus kebutuhan permodalan anggotanya. Tetapi selama pelaksanaan program PUAP yang dimulai tahun 2008 dan berakhir tahun 2015, LKMA yang sudah terbentuk hanya sebanyak 6.887 unit dari 52.186 Gapoktan/desa yang sudah menerima bantuan permodalan usaha pertanian. Dari 6.887 LKMA tersebut yang sudah mendapatkan izin usaha dari Otoritas Jasa Keuangan (OJK) sebanyak 155 LKMA.

Beberapa penyebab kenapa tidak seluruh Gapoktan yang membuat LKMA, yaitu: (i) karena didirikan atas inisiatif pemerintah maka status keanggotaan dan kepemilikan LKMA tidak jelas, (ii) ketidakjelasan ini juga terjadi pada pembagian hak dan kewajiban untuk setiap anggota dan pengurus, (iii) sulit mencapai skala ekonomis usaha dan sulit menjaga keberlangsungannya dan (iv) mengharapkan simpanan anggota dan non-anggota juga sulit, karena menyimpan dana di LKMA mempunyai risiko yang besar (Hanggana, 2018).

Hal ini bisa saja terjadi karena mendirikan kelembagaan bukanlah pekerjaan yang mudah, baik dari pembentukan awal maupun dari sisi menjalankan kelembagaan itu sendiri. Dibutuhkan waktu untuk bisa memantapkan eksistensi kelompok miskin dan kelembagaan terkait lainnya dengan sasaran pemberdayaan masyarakat miskin dan menumbuhkan ekonomi perdesaan (Darwis and Rusastra, 2011). Hal yang senada sebelumnya pernah dikemukan oleh Syahyuti (2007) dimana keberhasilan program pemberdayaan masyarakat dapat diwujudkan apabila ada pembenahan di sistem administrasi/aturan main dan birokrasinya.

Dari sisi lain, program PUAP dapat memberikan dampak positif berupa: (i) petani tidak susah mencari tambahan biaya usahatani, (ii) peningkatan adopsi teknologi dengan memanfaatkan traktor dalam mengolah lahan dan (iii) mampu meningkatkan produktivitas serta pendapatan (Hosen et al., 2014, Hafinuddin M, 2013). Meningkatnya pendapatan juga dikemukaan oleh Rompas et.al (2016) khususnya pada petani jagung di Desa Kawangkoan dengan hasil penelitian menunjukkan bahwa pada tingkat kepercayaan $\alpha=5 \%$, thitung $=7,628>$ tabel $=2,145$ atau telah terjadi peningkatan pendapatan dari Rp 9.179.066 sebelum mengikuti program menjadi Rp 15.526.133 setelah mengikuti program PUAP.

Menurut Darwis.V. (2018) program PUAP berhasil menggantikan pernyataan petani dari non bankable menjadi petani bankable. Hal ini dikarenakan petani pelaksana PUAP sudah terbiasa mengikuti pola perbankan, yaitu: (i) membuat surat permohonan pinjaman dan diketahui oleh pihak lain, (ii) dikenakan bunga pinjaman, (iii) lama meminjam dan keharusan menyicil setiap bulan, (iv) ada denda apabila tidak tepat waktu membayar cicilan, (v) dikenakan biaya administrasi dan provisi setiap kali meminjam, (vi) bahkan dibeberapa tempat pinjaman diatas 5 juta harus mempunyai anggunan.

Dengan adanya manfaat pelaksaan program PUAP, maka tulisan ini bertujuan ingin mengevaluasi bagaimana pelaksanaan dalam menjalankan Lembaga Keuangan Mikro Agribisnis (LKMA) bentukan dari program khususnya di LKMA yang sudah mendapatkan izin usaha dari Otoritas Jasa Keuangan (OJK).

\section{METODE PENELITIAN}

Pemilihan lokasi dilakukan sengaja (purposive), hal ini dikarenakan provinsi Lampung termasuk 4 provinsi yang LKMA nya sudah mendapatkan izin usaha dari OJK. Adapun 3 provinsi lainnya adalah : Sumatera Barat, Jawa Tengah dan Sulawesi Barat. Pelaksanaan program PUAP di provinsi Lampung sudah dilaksanakan semenjak tahun 2008 sampai dengan tahun 2015 di 1.832 Gapoktan atau sudah dilaksanakan di 1.832 desa (Tabel 1). Dalam perkembangannya dari 1.832 
Gapoktan, 129 Gapoktan sudah membentuk LKMA dan dari 129 LKMA yang terbentuk 6 diantaranya sudah mendapatkan izin usaha dari OJK.

Untuk mengevaluasi pelaksanaan LKMA, maka dipilih 4 LKMA yang sudah mendapatkan izin OJK yaitu: (i) LKMA Mekar Jaya yang terdapat di Desa Sriwijaya Kabupaten Lampung Tengah ; (ii) LKMA Panca Karya yang terdapat di Desa Panca Tunggal Kabupaten Lampung Selatan, (iii) LKMA Sumber Lestari yang terdapat di Desa Mekar Mulyo Kabupaten Lampung Timur dan (iv) LKMA Sari Makmur yang terdapat di Desa Tejo Sari Kota Metro.

Tabel 1. Lokasi dan Perkembangan Gapoktan Penerima PUAP 2008-2015

\begin{tabular}{|c|c|c|c|c|c|}
\hline \multicolumn{2}{|c|}{ Jumlah Gapoktan } & \multicolumn{2}{|c|}{ Jumlah LKMA } & \multicolumn{2}{|c|}{ LKMA sudah dapat Izin OJK } \\
\hline Kabupaten & Jumlah & Kabupaten & Jumlah & Kabupaten & Jumlah \\
\hline Kota Bandar Lampung & 1 & Kota Bandar Lampung & 0 & Kota Bandar Lampung & 0 \\
\hline Kota Metro & 18 & Kota Metro & 0 & Kota Metro & 1 \\
\hline Lampung Barat & 166 & Lampung Barat & 27 & Lampung Barat & 0 \\
\hline Lampung Selatan & 230 & Lampung Selatan & 0 & Lampung Selatan & 1 \\
\hline Lampung Tengah & 222 & Lampung Tengah & 50 & Lampung Tengah & 1 \\
\hline Lampung Timur & 219 & Lampung Timur & 0 & Lampung Timur & 1 \\
\hline Lampung Utara & 153 & Lampung Utara & 0 & Lampung Utara & 0 \\
\hline Mesuji & 69 & Mesuji & 0 & Mesuji & 0 \\
\hline Pesawaran & 132 & Pesawaran & 29 & Pesawaran & 0 \\
\hline Pesisir Barat & 1 & Pesisir Barat & 0 & Pesisir Barat & 0 \\
\hline Pringsewu & 99 & Pringsewu & 0 & Pringsewu & 0 \\
\hline Tanggamus & 194 & Tanggamu & 0 & Tanggamu & 0 \\
\hline Tulang Bawang & 137 & Tulang Bawang & 23 & Tulang Bawang & 2 \\
\hline Tulang Bawang Barat & 41 & Tulang Bawang Barat & 0 & Tulang Bawang Barat & 0 \\
\hline Way Kanan & 150 & Way Kanan & 0 & Way Kanan & 0 \\
\hline Total & 1.832 & Total & 129 & Total & 6 \\
\hline
\end{tabular}

Sumber : Direktorat Pembiayaan Kementerian Pertanian. 2018

Data yang dipergunakan terdiri dari data sekunder dan data primer. Data sekunder diperoleh dari Direktorat Pembiayaan Kementerian Pertanian. Data primer diperoleh dengan cara survay ke lokasi yang dilaksanakan pada awal bulan Oktober 2018. Pengumpulan data primer dilakukan melalui FGD bersama pengurus LKMA dengan mempergunakan pertanyaan terstruktur (kuesioner). Adapun topik diskusi dilakukan dengan penekanan kepada aspek kelembagaan, aspek pelaksanaan dan aspek perkembangan usaha. Data yang terkumpul tersebut kemudian dipergunakan untuk: (i) potret pelaksanaan LKMA mempergunakan metode tabulasi ; (ii) evaluasi pelaksanaan LKMA dengan mempergunakan metode rangking dan hasil analisa ditampilkan dalam bentuk tabel-tabel.

\section{HASIL DAN PEMBAHASAN}

\section{Aspek Kelembagaan}

Dari sisi aspek kelembagaan ada tiga point yang dilihat, yaitu tentang legalitas, kepemilikan asset dan sistem organisasi (Tabel 2). Untuk mendapat legalitas LKMA harus mengajukan persyaratan ke Dinas Koperasi, Perindustrian dan UKM Kabupaten Lampung Selatan, dengan melampirkan antara lain : Notulen rapat Anggota Pendirian Koperasi, Berita Acara, Daftar Hadir Peserta Rapat, Daftar Pengurus dan Pengawas, Konsep Anggaran Dasar, Daftar Nama-nama Pendiri, Neraca Awal, Bukti Penyertaan Modal, Rencana Kegiatan Awal Koperasi, foto copy KTP masing-masing anggota pendiri dan Surat dukungan dari desa. Dari 4 LKMA yang didatangi tersebut tiga sudah berbentuk badan hukum dan satu lagi masih dalam proses pembentukan badan hukum, yaitu : LKM Gapoktan Panca Karya.

Nama badan hukum yang terbentuk ada yang memakai kata Gapoktan seperti Koperasi LKMA Gapoktan Panca Karya dan Koperasi LKMA Gapoktan Sari Makmur. Dan ada juga yang tidak mempergunakan kata gapoktan seperti di Koperasi LKMA Mekar Jaya dan Koperasi LKMA Sumber Lestari. Ada dan tidak ada kata gapoktan di setiap LKMA disebabkan ketidakseragaman informasi 
yang diperoleh oleh pengurusnya. Hal ini direpresentasikan pada saat wawancara dimana menurut pengurus lebih baik badan hukumnya dibawah koperasi saja, karena tidak perlu ada pengawasan laporan keuangan. Oleh karena itu tidak perlu ada pencantuman kata Gapoktan. Sebaliknya menurut OJK harus ada kata Gapoktan dinama lembaga apabila ingin mendapatkan izin berusaha. Tetapi yang menariknya meskipun ada ketetapan pencantuman kata Gapoktan, tetapi dalam kenyataannya 4 LKMA yang didatangi sudah mendapatkan izin berusaha bersyarat dari OJK. Karena sudah berbentuk koperasi, maka semua LKMA sudah memiliki AD/ART dan sudah melaksanakan RAT sebanyak 2 sampai tiga kali.

Asset utama dalam melaksanakan kegiatan LKMA ialah kantor beserta perlengkapannya. Dari 4 LKMA yang didatangi 2 LKMA sudah berkerja di kantor sendiri dan 1 LKMA bekerja di kantor yang diperoleh melalui sewa. Satu LKMA yaitu Sumber Lestari belum mempunyai kantor dan untuk sementara ini pengurus bekerja disalah satu rumah pengurus. LKMA Mekar Jaya sudah memiliki kantor khusus mengelola simpan pinjam, dengan biaya sewa pertahun sebesar Rp. 4.000.000. Sementara LKMA Sari Makmur dan LKMA Panca Karya sudah memiliki kantor dengan status milik sendiri. Yang menjadi pembeda kalau di LKMA Sumber Lestari kantornya tidak hanya mengelola simpan pinjaman modal PUAP, tetapi juga mengelola kegiatan lainnya, seperti Lumbung Pangan Desa, mensuplai Toko Tani Indonesia, kegiatan Kelompok Wanita Tani. Sedangkan LKMA Panca Karya kantornya masih dalam bentuk saung pertemuan. Kantor LKMA Sari Makmur dibangun diatas tanah yang dibeli dengan mempergunakan hasil usaha dengan mempergunakan modal PUAP dan bangunannya diperoleh dari beberapa bantuan program pemerintah. Sedangkan LKMA Panca Karya bangunannya dibuat dari keuntungan dalam mengelola bantuan permodalan PUAP, sementara tanahnya diperoleh dari hibah.

Dalam menjalankan organisasi dibutuhkan pengurus dan seluruh LKMA yang didatangi sudah memiliki kepengurusan yang terdiri dari ketua, sekretaris dan bendahara. Jabatan tersebut dilaksanakan selama 5 tahun dalam setiap periode dan dapat dipilih kembali pada saat pelaksanaan RAT. Khusus untuk LKMA Mekar Jaya pengelolaan LKMA diserahkan ketenaga profesional, yang terdiri dari satu orang Manajer dengan gaji perbulan sebesar Rp. 2.000 .000 ; satu orang tenaga akuntansi dengan gaji perbulan sebesar Rp. 1.800 .000 ; satu orang teller dengan gaji perbulan sebesar Rp. 1.000.000 dan satu orang funding officer dengan insentif 3,5\% dari target plus uang makan dan kendaraan Rp. 350.000 perbulan. Tugas dari Funding Officer adalah mencari nasabah dengan target perbulan sebesar Rp. 20.000.000.

Tabel 2. Kelembagaan LKMA

\begin{tabular}{|c|c|c|c|c|}
\hline Uraian & Mekar Jaya & Panca Karya & Sumber Lestari & Sari Makmur \\
\hline \multicolumn{5}{|c|}{ Legalitas } \\
\hline Desa & Sriwijaya & Panca Tunggal & Mekar Mulyo & Tejo Sari \\
\hline Berdiri LKMA & 2015 & 2016 & 2015 & 2015 \\
\hline Sudah berbadan hukum & 1 & 0 & 1 & 1 \\
\hline Bentuk badan hukum & Koperasi LKMA & $\begin{array}{r}\text { Keperasi LKMA } \\
\text { Gapoktan }\end{array}$ & Koperasi LKMA & $\begin{array}{r}\text { Koperasi LKMA } \\
\text { Gapoktan }\end{array}$ \\
\hline Tahun Penetapan & 2015 & 0 & 2015 & 2016 \\
\hline Ditetapkan oleh & Menkop & 0 & Menkop & Menkop \\
\hline $\mathrm{AD} / \mathrm{ART}$ & 1 & 1 & 1 & 1 \\
\hline Pelaksanaan RAT & 3 & 3 & 2 & 2 \\
\hline Izin Ojk & 1 & 1 & 1 & 1 \\
\hline \multicolumn{5}{|c|}{ Asset } \\
\hline Mempunyai kantor & 1 & 1 & 0 & 1 \\
\hline Status kantor & Sewa & Milik & 0 & Milik \\
\hline Tahun Kepemilikan & 0 & 2012 & 0 & 2018 \\
\hline Biaya kepemilikan & 0 & 11.000 .000 & 0 & 250.000 .000 \\
\hline Tahun sewa & 2017 & 0 & 0 & 0 \\
\hline
\end{tabular}

43 | Volume 3, Nomor 1, Tahun 2019 


\begin{tabular}{|c|c|c|c|c|}
\hline Biaya sewa/tahun & 4.000 .000 & 0 & 0 & 0 \\
\hline Tanah & 0 & 1 & 0 & 1 \\
\hline Bangunan & 0 & 1 & 0 & 1 \\
\hline Komputer & 4 & 1 & 0 & 1 \\
\hline Laptop & 1 & 2 & 2 & 1 \\
\hline Alat Komunikasi & 1 & 0 & 0 & 0 \\
\hline Furniture & 1 & 1 & 1 & 1 \\
\hline \multicolumn{5}{|c|}{ Organisasi } \\
\hline Sruktur Organisasi & 1 & 1 & 1 & 1 \\
\hline \multicolumn{5}{|l|}{ Jabatan Organisasi } \\
\hline Ketua & 1 & 1 & 1 & 1 \\
\hline Sekretaris & 1 & 1 & 1 & 1 \\
\hline Bendahara & 1 & 1 & 1 & 1 \\
\hline Manajer & 1 & 0 & 0 & 0 \\
\hline Akunting & 1 & 0 & 0 & 0 \\
\hline Teller & 1 & 0 & 0 & 0 \\
\hline Funding Officer & 1 & 0 & 0 & 0 \\
\hline \multicolumn{5}{|l|}{ Lama Jabatan } \\
\hline Ketua & 5 & 5 & 5 & 5 \\
\hline Sekretaris & 5 & 5 & 5 & 5 \\
\hline Bendahara & 5 & 5 & 5 & 5 \\
\hline Manajer & 5 & 0 & 0 & 0 \\
\hline Akunting & 5 & 0 & 0 & 0 \\
\hline Teller & 5 & 0 & 0 & 0 \\
\hline Funding Officer & 5 & 0 & 0 & 0 \\
\hline \multicolumn{5}{|l|}{ Insentif } \\
\hline Ketua & SHU & SHU & SHU & SHU \\
\hline Sekretaris & SHU & SHU & SHU & SHU \\
\hline Bendahara & SHU & SHU & SHU & SHU \\
\hline Manajer & $2.000 .000 / \mathrm{bln}$ & 0 & 0 & 0 \\
\hline Akunting & $1.800 .000 / \mathrm{bln}$ & 0 & 0 & 0 \\
\hline Teller & $1.000 .000 / \mathrm{bln}$ & 0 & 0 & 0 \\
\hline Funding Officer & $1.000 .000 / \mathrm{bln}$ & 0 & 0 & 0 \\
\hline \multicolumn{5}{|l|}{ Pembinaan } \\
\hline Kementan & 1 & 1 & 1 & 0 \\
\hline Dinas Provinsi & 1 & 0 & 0 & 1 \\
\hline Dinas Kabupaten & 0 & 0 & 0 & 1 \\
\hline OJK & 1 & 1 & 1 & 1 \\
\hline PMT & 0 & 0 & 0 & 0 \\
\hline \multicolumn{5}{|l|}{ Syarat Anggota } \\
\hline Simpanan Pokok & 1.000 .000 & 25.000 & 100.000 & 100.000 \\
\hline Simpanan Wajib & 10.000 & 2.000 & 10.000 & 5.000 \\
\hline
\end{tabular}

Pengurus LKMA pernah mendapatkan pelatihan keuangan dari OJK, Dinas Koperasi Provinsi dan BPTP Lampung hanya pada saat program PUAP dimulai. Pembinaan dari tenaga PMT sudah tidak dilaksanakan selama 2 tahun ini. Hal ini disebabkan honor dan uang operasional sejak tahun 2015 tidak ada lagi anggarannya di Dinas Pertanian Provinsi dan Kabupaten. Meskipun sudah ada pembinaan kepada pengelola tetapi dalam pelaksanaannya pembinaan tentang laporan keuangan masih dibutuhkan. Sekarang laporan keuangannya masih berdasarkan inisiatif dan kretifitas dari pengurus.

Karena sudah menjadi bentuk koperasi, maka setiap orang yang akan menjadi anggota koperasi diharuskan mengikuti persyaratan membayar: (i) simpanan pokok cukup sekali bayar sebesar Rp. 100.000 untuk di LKMA Sumber Lestari dan Sari Makmur, serta Rp. 25.000 di LKMA Panca Karya. Sedangkan simpanan wajib diharuskan dibayar setiap bulan dan jumlah kewajibannya berbeda di setiap LKMA. Hal yang berbeda juga terjadi di LKMA Mekar Jaya, khususnya dalam penetapan kewajiban membayar simpanan pokok dan simpanan wajib. Kalau di 3 LKMA lainnya simpanan wajib dan simpanan pokok bisa bertambah mengikuti penambahan anggota. Tetapi di LKMA Mekar Jaya hanya simpanan wajib yang bertambah, sedangkan simpanan pokok tetap. Hal ini disebabkan karena yang dimaksudkan dengan simpanan pokok adalah kewajiban yang harus dibayar oleh para pendiri LKMA yang jumlahnya 20 orang. 


\section{Aspek Pelaksanaan Usaha}

Dalam aspek pelaksanaan yang dilihat dari sisi: (i) jenis usaha dan besaran bunga pinjaman, (ii) biaya-biaya lainnya yang timbul selain bunga pinjaman dalam setiap kali meminjam dan (iii) persyaratan lainnya (Tabel 3). Jenis usaha yang diberikan pinjaman modal oleh pengurus LKMA tidak sama disetiap LKMA. Usaha yang lebih beragam terdapat di LKMA Mekar Jaya dan bunga pinjaman juga disesuai dengan jenis usaha. Besaran bunga yang diterapkan terdapat di LKMA Mekar Jaya, yaitu sebesar 3\%/bulan untuk pinjaman dibidang usaha tanaman pangan. Sementara bunga yang terendah terdapat di LKMA Sumber Lestari, yaitu 1\%/bulan untuk semua jenis usaha. Selain bunga pinjaman perbulan peminjam dikenakan juga biaya lainnya seperti biaya provisi, administrasi, materai, denda telat membayar angsuran serta jaminan. Dalam pelaksanaan jenis biaya lain dan besarannya di masingmasing LKMA tidaklah sama.

Peminjam tidak hanya untuk anggota PUAP saja, tetapi anggota Non PUAP juga bisa meminjam. Bahkan peminjam bisa dilakukan melalui kelompok seperti yang terjadi di LKMA Sari Makmur dengan besaran pinjaman sebesar 20 juta. Setiap peminjam harus menyertakan anggunan dalam bentuk BPKB motor atau sertifikat lahan. Anggunan yang diperlukan di LKMA Mekar Jaya disesuaikan dengan jumlah pinjaman. Apabila meminjam antara 1 s/d 3 juta anggunannya BPKB motor atau SPT tanah. Kalau meminjam antara 5 s/d 10 juta anggunannya Akte Jual Beli dan kalau meminjam 15 s/d 20 juta anggunanya berupa sertifikat tanah (SHM). Sementara anggunan yang diperlukan bagi peminjan di LKMA Panca Karya cukup dalam bentuk surat persetujuan dari ketua kelompok.

LKMA sudah menerapkan kebijakan pemberian sangsi bagi peminjam yang terlambat membayar. Jenis dan penerapan sangsinya tidak sama untuk setiap LKMA. LKMA yang sudah menerapkan sangsi dalam bentuk uang adalah LKMA Mekar Jaya dan LKMA Sumber Lestari. Kreditur yang terlambat membayar angsuran akan dikenakan sangsi sebesar Rp 5.000 perhari untuk LKMA Mekar Jaya dan 0,01\% untuk LKMA Sumber Lestari. Sementara LKMA Sari Makmur dan LKMA Panca Karya menerapkan sangsi masih dalam bentuk surat peringatan dengan memberikan langsung kepada peminjam. Apabila tetap tidak membayar, maka si peminjam tidak akan mendapatkan pinjaman lagi untuk masa masa yang akan datang. Sebaliknya yang melaksanakan pemberian reward untuk peminjam yang berkelakuan baik hanya LKMA Mekar Jaya saja. Adapun bentuk penghargaan yang diberikan antara lain: penurunan bunga pinjaman atau menambah waktu pinjaman dengan bunga tetap.

Tabel 3. Pelaksanaan LKMA

\begin{tabular}{|c|c|c|c|c|}
\hline Uraian & Mekar Jaya & Panca Karya & Sumber Lestari & Sari Makmur \\
\hline \multicolumn{5}{|c|}{ Bunga pinjaman perbulan } \\
\hline Tanaman Pangan & 3 & 2 & 1 & 2 \\
\hline Tanaman Perkebunan & 2,5 & 2 & 0 & 0 \\
\hline Tanaman Hortikultura & 2,5 & 0 & 1 & 1,7 \\
\hline Peternakan & 2,5 & 0 & 0 & 0 \\
\hline Pemasaran/Perdagangan & 0 & 0 & 1 & 1,5 \\
\hline Pengolahan Hasil & 0 & 0 & 0 & 1,5 \\
\hline \multicolumn{5}{|c|}{ Biaya lainnya } \\
\hline Provisi & $2,4 \%$ & 0 & 0 & 0 \\
\hline Administrasi & 0 & 0 & $1 \%$ & $1 \%$ \\
\hline Materai & 0 & 7.000 & 7.000 & 7.000 \\
\hline Keterlambatan & $5.000 /$ hari & 0 & $0,01 \%$ & 0 \\
\hline Jaminan & Satu kali angsuran & 0 & 0 & 0 \\
\hline \multicolumn{5}{|c|}{ Persyaratan lainnya } \\
\hline \multicolumn{5}{|l|}{ Nasabah: } \\
\hline Anggota PUAP & 1 & 1 & 1 & 1 \\
\hline Anggota Non PUAP & 1 & 1 & 1 & 1 \\
\hline \multicolumn{5}{|l|}{ Anggunan : } \\
\hline $\mathrm{Ya}$ & 1 & 0 & 1 & 1 \\
\hline Tidak & 0 & 1 & 0 & 0 \\
\hline
\end{tabular}

45 | Volume 3, Nomor 1, Tahun 2019 


\begin{tabular}{|c|c|c|c|c|}
\hline \multicolumn{5}{|l|}{ Batasan Pinjaman: } \\
\hline Terendah & 1.000 .000 & 500.000 & 500.000 & 500.000 \\
\hline Tertinggi & 20.000 .000 & 6.000 .000 & 5.000 .000 & $20.000 .000 *$ \\
\hline Punishment & 1 & 1 & 1 & 1 \\
\hline Reward & 1 & 0 & 0 & 0 \\
\hline Kemitraan & 1 & 0 & 0 & 1 \\
\hline Perencanaan 1 thn & 1 & 1 & 1 & 1 \\
\hline Pembagian SHU (\%) & 1 & 0 & 1 & 0 \\
\hline Ketua Gapoktan & 20 & & 10 & \\
\hline Pengelola LKMA & 15 & & 10 & \\
\hline Pembina & 5 & & 10 & \\
\hline Cadangan Modal & 30 & & 40 & \\
\hline Sosial & 5 & & 0 & \\
\hline Pendidikan & 5 & & 0 & \\
\hline Anggota & 10 & & 30 & \\
\hline Pembangunan & 5 & & 0 & \\
\hline
\end{tabular}

Dalam menjalankan usahanya LKMA Mekar Jaya dan LKMA Sari Makmur sudah membuat kemitraan dengan pihak lainnya. Kemitraaan yang dibangun oleh LKMA Sari Makmur adalah kemitraan jasa dalam bentuk pembayaran rekening listrik. Sementara kemitraan yang dijalankan oleh LKMA Mekar Jaya adalah kemitraan bisnis dengan pabrik tapioka. Mekanisme yang dipergunakan ialah: pabrik tapioka menginvestasikan modal ke LKMA Mekar Jaya dan pabrik akan mendapatkan keuntungan dalam bentuk bunga sebesar $0,8 \%$ perbulan. Selain itu pabrik juga akan mendapatkan jaminan bahan baku ubi kayu dari LKMA Mekar Jaya. Adapun ubi kayu tersebut diperoleh dari anggota Gapoktan yang meminjam modal ke LKMA Mekar Jaya. Dari sisi LKMA Mekar Jaya manfaat investasi pabrik tapioka, yaitu tambahan modal usaha. Untuk tahun sekarang sudah ada 3 pabrik tapioka yang menginvestasikan modal ke LKMA Mekar Jaya dengan nilai total investasi sebesar Rp. 150.000 .000

Lembaga yang sudah berbentuk koperasi, harusnya setiap tahun melaksanakan Rapat Anggota Tahunan (RAT). LKMA yang didatangi sudah melaksanakan RAT antara 2 sampai 3 kali. Dalam setiap RAT tersebut selain pengurus melaporkan pertanggungjawabannya dalam satu tahun berjalan, juga disampaikan tentang perencanaan 1 tahun kedepan. Satu lagi kegiatan yang ditunggu-tunggu oleh anggota koperasi adalah pembagian Sisa Hasil Usaha (SHU). Tetapi yang melaksanakan pembagian SHU hanya LKMA Mekar Jaya dan LKMA Sumber Lestari saja. Sedangkan LKMA yang lainnya tidak melakukan pembagian SHU karena seluruh pendapatannya yang dihasilkan dimasukkan lagi sebagai tambahan modal usaha.

\section{Aspek Perkembangan Usaha}

Perkembangan anggota yang meminjam di semua LKMA mengalami peningkatan dan peningkatan yang paling tinggi terjadi di LKMA Mekar Jaya, yaitu naik dari 107 orang pada tahun 2015 menjadi 280 orang pada tahun 2017 atau mengalami penambahan sebanyak 173 orang selama 3 tahun. Kondisi yang sama juga terjadi dalam penambahan modal, dimana LKMA Mekar Jaya mengalami penambahan modal selama 3 tahun sebesar 920 juta atau mengalami kenaikan modal usaha dari 150 juta pada tahun 2015 menjadi satu milyar tujuh puluh juta pada tahun 2017 (Tabel 4). Sebaliknya yang paling sedikit penambahan anggota yang meminjam terjadi di LKM Panca Karya, yaitu bertambah hanya 3 orang selama 2 tahun. Sementara LKMA Sumber Lestari justru mengalami penurunan modal usaha dari Rp. 175.898 .000 pada tahun 2016 menjadi Rp. 155.770.000 pada tahun 2017. Penyebab menurunnya modal di LKMA Sumber Lestari, karena banyak anggota yang mengambil tabungannya. 
Tabel 4. Perkembangan Usaha

\begin{tabular}{lcccc}
\hline \multicolumn{1}{c}{ Uraian } & \multicolumn{2}{c}{ Tahun } & Tahun 2017 & Perkembangan \\
& Awal & $\begin{array}{c}\text { jumlah } \\
\text { Orang/nominal }\end{array}$ & \\
\hline Mekar Jaya & & Perkembangan angota yang meminjam & 173 \\
Panca Karya & 2015 & 107 & 280 & 3 \\
Sumber Lestari & 2016 & 71 & 74 & 16 \\
Sari Makmur & 2016 & 25 & 41 & 15 \\
\hline & 2015 & 35 & 50 & 920.000 .000 \\
\hline Mekar Jaya & & Perkembangan modal LKMA & 45.078 .000 \\
Panca Karya & 2015 & 150.000 .000 & 1.070 .000 .000 & -20.128 .000 \\
Sumber Lestari & 2014 & 119.822 .000 & 164.900 .000 & 103.244 .300 \\
Sari Makmur & 2016 & 175.898 .000 & 155.770 .000 & 218.445 .500 \\
\hline
\end{tabular}

\section{Peringkat LKMA}

Peringat LKMA berdasarkan; (i) aspek kelembagaan dilihat dari ketersediaannya, apabila memiliki maka dikasih point satu dan sebaliknya apabila tidak ada dikasih point nol. Dari penilaian tersebut, maka terpilih LKMA Mekar Jaya yang paling tinggi dengan nilai 9 ; (ii) aspek pelaksanaan usaha, point satu akan diberikan kepada LKMA: lebih dari 4 jenis usaha yang diberikan pinjaman modal ; menerapkan bunga berbeda mengikuti jenis usaha ; mempergunakan materai dan memberikan denda keterlambatan dalam membayar anggusaran ; pinjaman diberikan kepada angota atau non anggota PUAP ; serta mewajibkan peminjam melampirkan agunan dalam setiap kali meminjam. Dari variabel penilaan tersebut LKMA yang paling banyak pointnya adalah LKMA Mekar Jaya ; (iii) aspek perkembangan usaha kembali LKMA Mekar Jaya yang paling tinggi, yaitu mengalami peningkatan rata-rata pertahun sebesar $168,5 \%$. Untuk melihat lebih rinci tentang perhitungan peringkat LKMA dapat dilihat pada tabel 5 dibawah ini. 
Tabel 5. Cara Perhitungan Peringkat LKMA

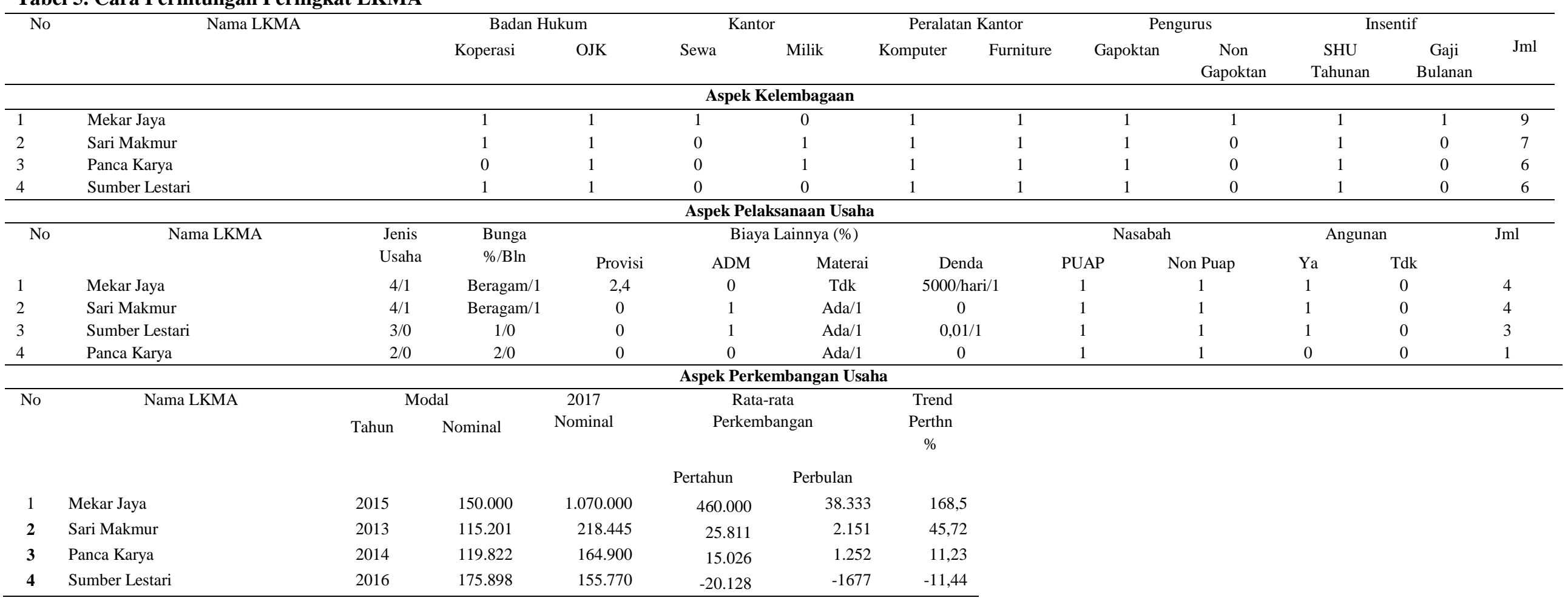




\section{KESIMPULAN DAN SARAN Kesimpulan}

LKMA Mekar Jaya merupakan LKMA yang paling bagus dibandingkan dengan LKMA yang lainnya. Hal ini terlihat dari: (i) aspek kelembagaan yang sudah memiliki legalitas berusaha baik dari Kementerian Koperasi maupun dari OJK, sudah bekerja dikantor berikut dengan perangkatnya, mempekerjakan tenaga profesional dengan insentif perbulan ; (ii) dari aspek pelaksanaan usaha yang memberikan pinjaman keberbagai usaha yang membedakan besaran bunga berdasarkan jenis usaha, setiap peminjam dikenakan biaya provisi dalam setiap kali meminjam dan peminjam adalah masyarakat sekitar yang boleh meminjam asal mengikuti persyaratan dan mempunyai anggunan ; (iii) dari aspek perkembangan usaha yang meningkat setiap tahun baik dari sisi jumlah peminjam maupun dari sisi penambahan modal usaha.

\section{DAFTAR PUSTAKA}

Badan Ketahanan Pangan (2009) Pedoman Umum Program Aksi Desa Mandiri Pangan. Jakarta.

Darwis.V. (2018) Pembentukan Lembaga Pembiayaan Pertanian. Jakarta.

Darwis, V. and Rusastra, I. W. (2011) 'Optimalisasi Pemberdayaan Masyarakat Desa Melalui Sinergi Program PUAP dengan Desa Mandiri Pangan’, Analisis Kebijakan Pertanian, 9(2), p. 125. doi: 10.21082/akp.v9n2.2011.125-142.

Hafinuddin M, A. M. dan Y. . S. (2013) 'Hubungan Dinamika Gapoktan Dengan Keberhasilan Program Pengembangan Usaha Agribisnis Perdesaan.', Ilmu Pertanian dan Perikanan, 2(2), pp. 93-97.

Hosen, N. et al. (2014) 'Peranan LKM-A dalam Mendorong Percepatan Adopsi Teknologi Jagung di Sumatera Barat Microfinance Role to Acceleration Adoption of Corn Technology in West Sumatra', 14(1), pp. 22-30.

Rompas, I. S., Dumais, J. N. K. and Talumingan, C. (2016) 'PUAP untuk penyaluran bantuan modal usaha bagi anggota. Untuk mencapai hasil yang maksimal dalam pelaksanaan PUAP , Gapoktan di dampingi oleh tenaga penyuluh pendamping dan penyelia mitra tani ( PMT ). Melalui pelaksanaan PUAP diharapkan Gapoktan dapat m', 13, pp. 183-188.

Sri Hanggana (2018) 'Regulations Weakness Analysis of Farmers Group, Gapoktan, UPJA, and LKM-A in Order to Enhance Farmers' Income', Jurnal Analisis Kebijakan Pertanian, 15(2), pp. 137-149.

Syahyuti, N. (2007) 'Penerapan Pendekatan Pemberdayaan dalam Kegiatan Pembangunan Pertanian: Perbandingan Kegiatan P4K, PIDRA, P4MI, dan Primatani', Forum penelitian Agro Ekonomi, 25(2), p. 104. doi: 10.21082/fae.v25n2.2007.104-116. 